УДК 65.011.1: 629.4.084.1

JEL: D24, M11

DOI: $10.17213 / 2312-6469-2019-6-152-157$

МЕТОДИКА АВТОМАТИЗАЦИИ ПРОЦЕССА МАТЕРИАЛЬНО-ТЕХНИЧЕСКОГО ОБЕСПЕЧЕНИЯ ПРОИЗВОДСТВА МАШИНОСТРОИТЕЛЬНОГО ПРЕДПРИЯТИЯ

\author{
(C) Д.В. Банников, А.М. Потехин 2019
}

Южно-Российский государственный политехнический университет (НПИ) им. М.И. Платова, г. Новочеркасск, Россия

Статья посвящена вопросам автоматизации процесса материально-технического обеспечения производства машиностроительного предприятия.

Ключевые слова: автоматизачия, материально-техническое обеспечение, машиностроение.

\title{
TECHNIQUE OF AUTOMATION OF PROCESS OF MATERIAL AND TECHNICAL SUPPORT OF PRODUCTION OF THE MACHINE-BUILDING ENTERPRISE
}

\author{
(C) D.V. Bannikov, A.M. Potehin 2019 \\ Platov South-Russian State Polytechnic University (NPI), \\ Novocherkassk, Russia
}

The article is devoted to the automation of the process of material and technical support for the production of machine-building enterprises.

Keywords: automation, material and technical support, mechanical engineering.

Отрасль российской машиностроительной промышленности насчитывает более 120 крупнейших предприятий, в которые входят и локомотивостроительные заводы [6].

Основой для реализации всех производственных процессов на предприятиях является обеспечение товарно-материальными ценностями (ТМЦ).

На подобных предприятиях осуществляется постоянная модернизация и автоматизация всех видов производственных процессов, включая процесс обеспечения ТМЦ. 
В связи с появлением новых видов подвижного состава и модернизацией существующих возникает проблема эффективного и своевременного снабжения производств ТМЦ. Первоочередной задачей данного процесса является взаимодействие между заказчиками и поставщиками. Эффективное управление данным взаимодействием позволяет оптимальным образом реализовать процесс обеспечения ТМЦ.

На большинстве крупных российских предприятий процесс материально-технического обеспечения (МТО) организован следующим образом:

- производственно-диспетчерское управление (ПДУ) ежемесячно направляет в службу МТО производственный план на последующие 1-2 месяца;

- служба МТО на основании данного плана формирует портфель заказов (виды и количества ТМЦ);

- производится выбор поставщиков с учетом цены, сроков изготовления и поставки;

- служба МТО осуществляет контроль за сроками изготовления ТМЦ и проводит ранжирование типов продукции по приоритетам согласно производственному плану;

- по факту изготовления продукции служба МТО обеспечивает доставку ее на склад и сообщает ПДУ о сроках прибытия;

- по мере получения заявок от цехов служба МТО производит передачу ТМЦ со склада на производство $[1,5]$.

Описанный процесс МТО на локомотивостроительных предприятиях в лучшем случае автоматизирован частично. Однако для достижения максимального эффекта и удовлетворения уровня современного производства автоматизация процесса МТО должна быть автоматизирована в полном объеме [1].

Исследование алгоритмов процесса МТО проводилось и ранее, однако целью данной работы является разработка алгоритмов применительно к конкретному предприятию, с учетом сложившейся специфики деятельности подразделения МТО.

Первым шагом к полной автоматизации МТО является разработка алгоритмов процесса:

- алгоритм расчета потребности в ТМЦ;

- алгоритм выбора оптимального поставщика;

- алгоритм доставки ТМЦ на склад предприятия;

- алгоритм выдачи ТМЦ со склада на производство [3, 4].

Разработанные алгоритмы являются основой для создания программного обеспечения системы автоматизированного управления (САУ).

Рассмотрим более подробно каждый из алгоритмов.

Алгоритм 1 - Расчет потребности в ТМЦ (рис. 1). В системе формируются данные по потребности ТМЦ с учетом производственного плана и 


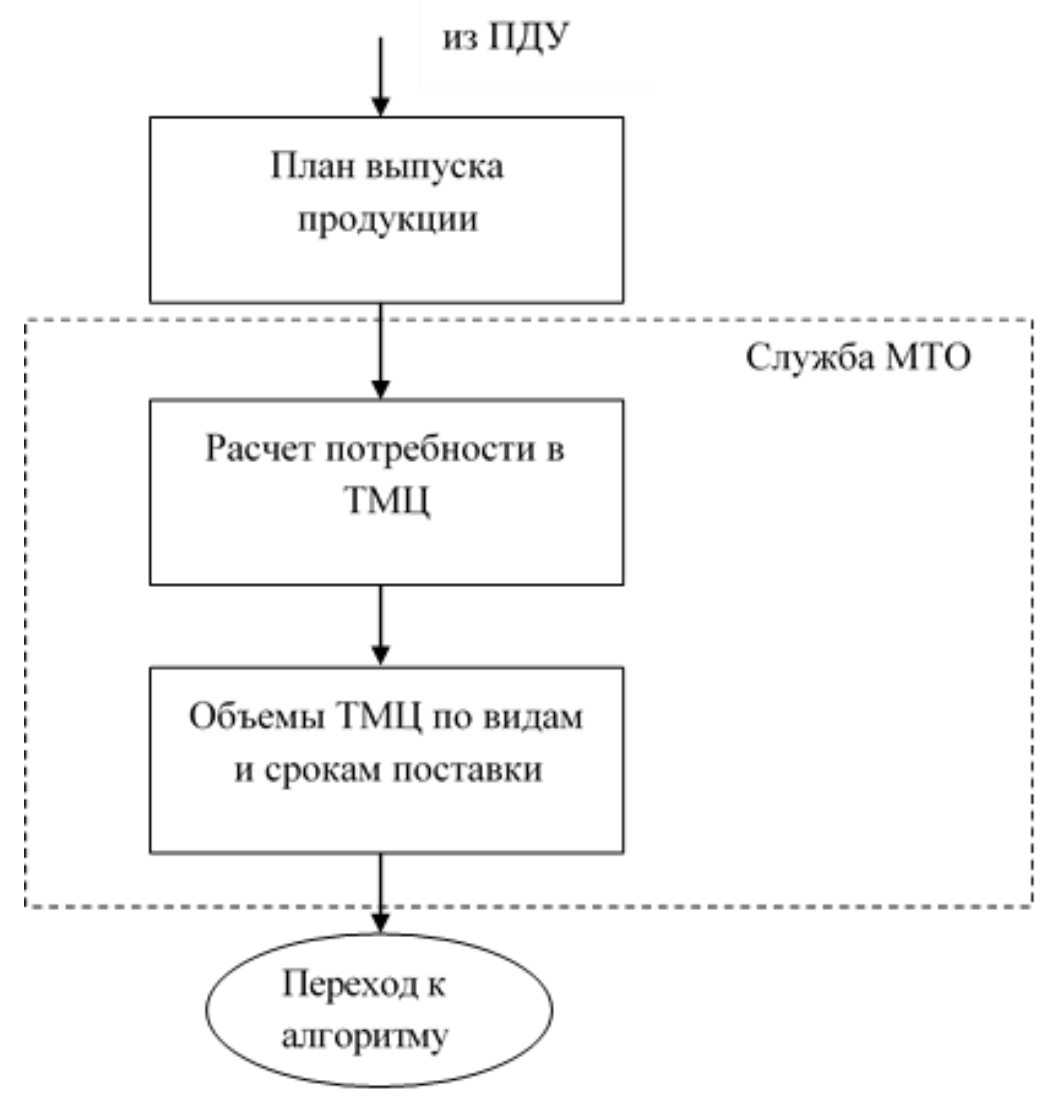

Рис. 1. Алгоритм 1 - Расчет потребности в ТМЦ

незавершенного производства для каждого конкретного цеха (производства). На основе этих данных производится расчет потребного на последующий квартал количества и вида ТМЦ с учетом минимальных норм отгрузки и сроков поставки (логистические параметры).

Таким образом, создается страховой запас, учитывающий квартальную потребность производства в ТМЦ [3].

Алгоритм 2 - Выбор оптимального поставщика (рис. 2). На основе полученного в результате осуществления первого алгоритма количества и типов ТМЦ производится выбор оптимальных поставщика/поставщиков по следующим критериям:

- вид ТМЦ;

- объем поставки;

- цена;

- сроки поставки;

- качество поставляемой продукции;

- опыт работы с данным поставщиком.

По результатам выбора поставщика/поставщиков производится автоматическое формирование закупочных процедур, в том числе для тендера, если предусматривается его проведение, когда единственный поставщик не определен (техническое задание, документация закупки, проект договора и пр.). 


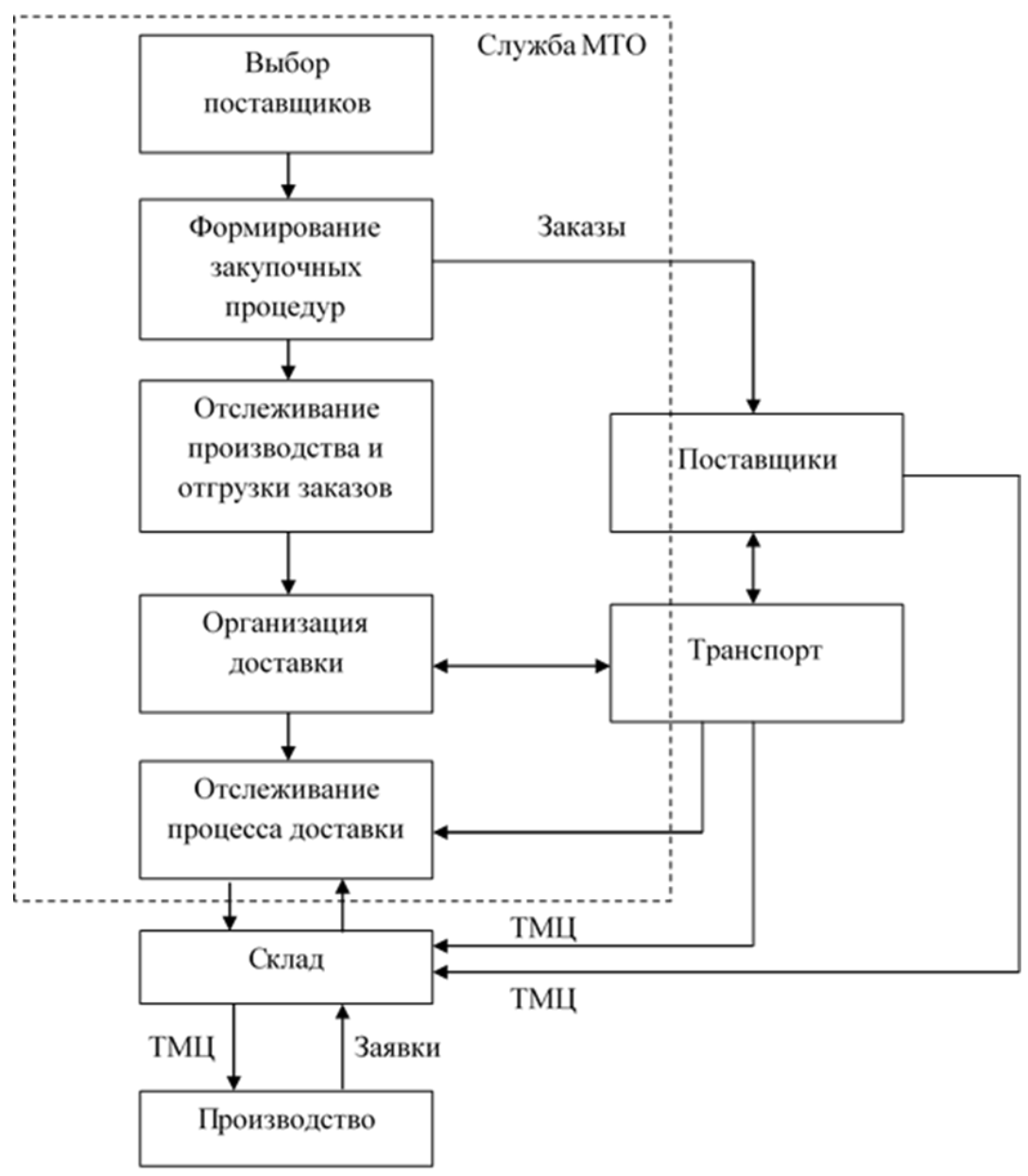

Рис. 2. Алгоритмы 2-4 - Выбор поставщика, доставка и выдача ТМЦ

Необходимо отметить, что процедура проведения тендера не всегда является оптимальной, т.к. увеличивает суммарное время поставки, и не всегда позволяет выбрать наилучшего поставщика $[4,5]$.

Следующим этапом этого алгоритма является автоматическое сопровождение закупочной процедуры от подачи заявки до факта изготовления заказанной продукции. Здесь должна обеспечиваться возможность отслеживания всех следующих событий процесса поставки:

- подача заявки;

- заключение договора/контракта;

- процесс оплаты;

- факт изготовления/отгрузки продукции.

Алгоритм 3 - Доставка ТМЦ на склад предприятия (рис. 2). Включает в себя следующие этапы:

- ранжирование по видам поставки ТМЦ (самовывоз, доставка силами поставщика, услугами транспортных компаний);

- организация доставки ТМЦ силами предприятия-заказчика, которая включает в себя заказ транспортного средства, определение тоннажа и габаритов доставляемого груза; 
- отслеживание этапов доставки ТМЦ как транспортом предприятия, так и транспортом сторонних организаций до момента прибытия на склад [5].

Алгоритм 4 - Выдача ТМЦ со склада на производство (рис. 2). Этот алгоритм использует базу данных ТМЦ, имеющихся на складе, оперативно актуализируемую с учетом поступления ТМЦ от поставщиков и выдачи их в производство. При этом должны отмечаться критические (недостаточные) объемы и виды ТМЦ для оперативного и своевременного их пополнения. В этом же алгоритме используются автоматическая система приема заявок цехов и организация выдачи ТМЦ по этим заявкам (т.е. по каналу обратной связи цех-заявитель получает ответ, содержащий дату, время и место получения заявленного ТМЦ на складе предприятия) $[1,3,4]$.

Таким образом, можно сделать вывод, что при подходе, основанном на оценке показателей надежности, решается несколько задач материальнотехнического обеспечения в условиях эксплуатации подвижного состава в течение всего жизненного цикла: обеспечение точности планирования затрат на обслуживание подвижного состава и оптимизация многономенклатурных запасов оборудования и запасных частей для поддержания заданного коэффициента технической готовности [2].

Таким образом, с использованием данных алгоритмов процесса, исследованных для конкретного предприятия, возможна модернизация существующего процесса с применением современного программного обеспечения (ПО). В качестве такого ПО, к примеру, может быть использована платформа системы $1 \mathrm{C}$ с модернизацией и/или синтезом нового вида данной системы с внедрением в нее новых дополнительных блоков.

При внедрении вышеуказанной модернизации открывается возможность сокращения запасов продукции, минимизация простоев цехов-потребителей и обеспечивается оптимальный выбор поставщика, что в совокупности позволяет значительно сократить финансовые и временные затраты предприятия [2].

\section{Литература}

1. Архангельский Г.А. Корпоративный тайм-менеджмент: Энциклопедия решений / Г.А. Архангельский. - М: Изд. Альпина Паблишер, 2017.

2. Спилберг С. МВА за 10 дней: Самое важное из программ ведущих бизнес-школ мира / С. Спилберг. - М: Изд. Альпина Паблишер, 2017.

3. Голдрат Э. Критическая цепь / Э.Голдрат. - М: Изд. Альпина Паблишер, 2014.

4. Смирнова Е.А. Управление Цепями Поставок / Е.А. Смирнова. - СПб.: Изд. СанктПетербургского Университета Экономика и Финансов, 2009.

5. СМБ. Процесс закупок. Оценка и выбор поставщиков. СТП СК 06.01-2018.

6. Промышленное производство // Официальный сайт Федеральной службы государственной статистики. [Электронный pecypc]: http://www.gks.ru/wps/wcm/connect/ rosstat_main/rosstat/ru/statistics/enterprise/industrial/\#/ [дата обращения 27.12.2019]. 
Банников Дмитрий Викторович - студент магистратуры ФГБОУ ВО «Южно-Российский государственный политехнический университет» им. М.И. Платова, г. Новочеркасск, Россия.

Bannikov Dmitry V. - Master student of Platov South-Russian State Polytechnic University (NPI), Novocherkassk, Russia.

Потехин Алексей Михайлович - студент магистратуры ФГБОУ ВО «Южно-Российский государственный политехнический университет», г. Новочеркасск, Россия.

Potekhin Aleksey M. - Master student of Platov South-Russian State Polytechnic University (NPI), Novocherkassk, Russia.

Россия, 346428, г. Новочеркасск, ул. Просвещения, 132

132, st. Prosveshcheniya, Novocherkassk, 346428, Russia

e-mail: alekceypotehin@gmail.com 